\title{
Apresentação
}

\section{Tudo o que você sempre quis saber sobre aula teórica, mas ninguém teve coragem de te ensinar!}

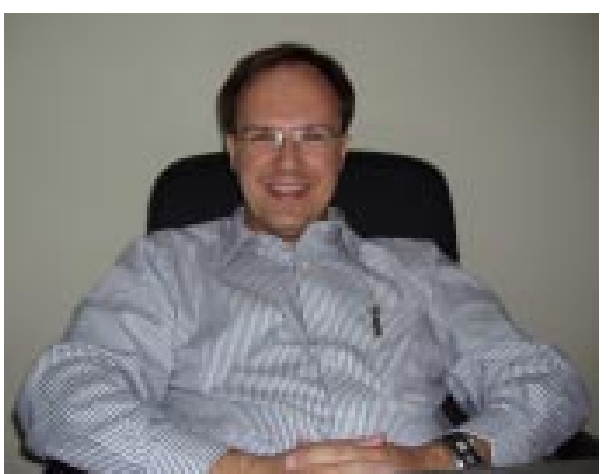

Antonio Pazin Filho

Coordenador do Simpósio Docente do Departamento de Clínica Médica da FMRP-USP
$\mathrm{W}_{\mathrm{B}}$ oody Allen aplicado à Didática!!!! Foi desta forma que foi realizada a abertura da disciplina de pós-graduação RCM 5812 Aplicaşão dos Princípios de Didática em Aulas Teóricas Formais da Faculdade de Medicina de Ribeirão Preto -USP nas cinco turmas (totalizando 60 alunos) realizadas até o final de 2005. Essa disciplina foi criada e ministrada pela primeira vez em 2003, contando com um número de inscritos de 84 alunos para as 10 vagas disponíveis, o que motivou o oferecimento da disciplina em caráter semestral em 2004 e 2005.

Esta procura excessiva resulta de dois pontos importantes. O primeiro é que o assunto é considerado obrigatório pelo programa de pós-graduação da USP e o segundo, que há extrema escassez de cursos que tratem sobre o assunto. Posteriormente, à medida que o curso foi sendo desenvolvido, e apreciado pelos alunos que participaram, pode-se dizer também que um terceiro motivo foi fruto da sua efetividade.

Esta disciplina busca dar subsídios aos alunos de pós-graduação para elaboração das aulas de qualificação e defesa de seus projetos e está embasada na experiência didática oriunda dos cursos de Suporte Avançado de Vida em Cardiologia (SAVC/ACLS) e em Trauma (ATLS). Ela foi desenvolvida em parceria com os professores André Schmidt do Departamento de Clínica Médica e Sandro Scarpelini do Departamento de Cirurgia e Anatomia e se caracteriza por ensinar técnicas de utilização dos recursos audiovisuais e modos de apresentação em aulas formais. A proposta é que os alunos elaborem uma aula de quinze minutos sobre um tema de sua área de atuação e a apresentem para o grupo, que provê "feed-back" para diversos dos aspectos pertinentes a uma apresentação.

Pode-se observar que a disciplina foi desenvolvida para ser o mais prática possível e trabalhar com as dificuldades de cada um dos alunos, num processo de ensino baseado em tarefas. Embora extremamente apreciado, muitos dos alunos solicitaram material para leitura complementar. Ao procurarmos material para esta finalidade, no entanto, nos deparamos com o fato de apesar de haver muito material publicado sobre o assunto, o material apresentado no curso era proveniente de várias fontes distintas, incluindo manuais de ins- 
trutores dos cursos, sendo difícil selecionar apenas uma ou duas referências. Outro ponto é que, apesar de muito do material ser destinado para ensino de adultos, as necessidades de ensino médico podem ser diferentes e exigir algumas adaptações. Desta necessidade de se fornecer um material mais coeso sobre o conteúdo do curso é que este simpósio nasceu. Além desta finalidade, ele também é um momento de reflexão para os envolvidos, possibilitando a reestruturação do curso e o desenvolvimento de novas propostas e seqüência da atividade.

O simpósio se inicia contextualizando a aula teórica como método de ensino e colocando alguns princípios de quando ela pode ser utilizada (capítulo 1). Seguem-se alguns princípios gerais de aprendizado do adulto (capítulo 2) que devem ser considerados em todas as fases de uma aula teórica, desde a sua elaboração, passando pelo período em que a apresentamos e continuando para a fase posterior, quando reavaliamos o que foi apresentado para futuras experiências. Depois desta aproximação geral, iremos nos concentrar na fase da elaboração da aula, considerando primeiramente as questões pertinentes ao conteúdo (capítulo 3) e, posteriormente, as questões pertinentes à for- ma (capítulo 4). A apresentação da aula propriamente dita inclui habilidades específicas, como a escolha e utilização de um recurso audio-visual de modo adequado (capítulo 5) e técnicas de interação com a platéia (capítulo 6). Finalmente, será apresentado um trabalho de análise qualitativa da experiência adquirida com os primeiros grupos de alunos da disciplina RCM 5812-Aplicação dos Princípios de Didática em Aulas Teóricas Formais, para os quais registro o meu agradecimento por terem possibilitado esta experiência tão bem sucedida.

Espera-se que este simpósio possa atingir os objetivos propostos e auxiliar alunos e professores na difícil empreitada de apresentar/assistir uma aula teórica. Jamais é demais enfatizar que a aula teórica é uma interação e que apesar de fornecermos aqui várias ferramentas para aqueles que se aventuram no papel de professor, os alunos tem também uma enorme responsabilidade no sucesso de qualquer atividade. Muitas vezes, apesar de todo o preparo para a atividade, não seremos capazes de atingir todos os nossos objetivos ou todas as pessoas presentes. Principalmente se o esforço para nos fazermos ser compreendidos não for acompanhado pelo esforço de nossos alunos de nos tentar compreender. 